\title{
ポリ(1-トリメチルシリル-1-プロピン)／ポリ（フェニル アセチレン）ブレンド膜の気体透過特性
}

\author{
永井一清*1 ・樋口亜紺*2 ・仲川 勤*3
}

*1ノースカロライナ州立大学工学部化学工学科 Box 7905, Raleigh, NC 27695-7905, USA

*2成蹊大学工学部工業化学科 焉 180-8633 東京都武蔵野市吉祥寺北町 3-3-1

*3明治大学理工学部工業化学科 焉 214-0033 神奈川県川崎市多摩区東三田 1-1-1

\section{Gas Permeation Properties of Poly(1-trimethylsilyl-1- propyne)/Poly(phenylacetylene) Blends}

\author{
Kazukiyo Nagai ${ }^{* 1}$, Akon Higuchi ${ }^{* 2}$, and Tsutomu Nakagawa ${ }^{* 3}$ \\ ${ }^{* 1}$ Department of Chemical Engineering, North Carolina State University \\ Box 7905, Raleigh, NC 27695-7905, USA \\ *2 Department of Industrial Chemistry, Seikei University, \\ 3-1 Kichijoji Kitamachi 3, Musashino, Tokyo 180-8633, Japan \\ ${ }^{* 3}$ Department of Industrial Chemistry, Meiji University \\ Higashi-mita, Tama-ku, Kawasaki 214-0033, Japan (correspoinding \\ author)
}

Gas permeation properties of poly(1-trimethylsilyl-1-propyne) [PMSP]/poly (phenylacetylene) [PPA] blends are reported. As PPA content in these blends increases, gas permeability decreases, while gas separation factors and blend film density increase. For a pure PMSP film, the order of gas permeability coefficients is $\mathrm{CO}_{2}>\mathrm{CH}_{4} \geqq \mathrm{H}_{2}>\mathrm{O}_{2}>\mathrm{N}_{2}$. However, for PMSP/PPA blend films, the permeability of $\mathrm{CH}_{4}$ is lower than that of $\mathrm{H}_{2}$. As a result, the ranking of gas permeabilities in PMSP/PPA blend films becomes $\mathrm{CO}_{2}>\mathrm{H}_{2}>\mathrm{CH}_{4}>\mathrm{O}_{2}>\mathrm{N}_{2}$. Furthermore, the reduction in the ratio of blend permeability to PMSP permeability is greater for a larger penetrant than for a smaller penetrant. This reduction in blendto-PMSP permeability ratio is smaller for PMSP/PPP blends than for the previously reported PMSP/ poly(1-phenyl-1-propyne) [PPP] blends at the same PPA and PPP contents.

Key words : poly (1-trimethylsilyl-1-propyne)/poly(phenylacetylene)/poly (1-phenyl-1-propyne)/ polymer blend/gas permeability 


\section{1. 緒 言}

ポリ (1-トリメチルシリル-1-プロピン) (PMSP, Fig. 1) は, 現在, 最も高い気体透過係数を 有する高分子である ${ }^{1)}$. それ故, 種々の方面から PMSP を用いての研究が進められてきている.

この PMSP を分離膜として実際に使用する上 で最大の問題となっているのが, 気体透過性の劣 化現象である ${ }^{2)}$. 著者らは, 特に, これらの劣化 現象の解明と気体透過性の安定化の研究を行って きている. その過程で, PMSP と他の置換アセ チレン重合体であるポリ（1-フェニル-1-プロピ ン) (PPP, Fig. 1) とのブレンド膜において, 高い気体透過性を維持しつつ, かつ良好な安定性 が得られた事を報告した ${ }^{3)}$ 。この PMSP/PPP ブレンド中の, PPP 含有量が増加するにつれて ブレンド膜の気体透過性は減少し, 気体分離性は 増加した. この際の透過挙動は, 均一ブレンドに 対する気体透過性のモデル式には完全には当ては まらなかった. PMSP/PPP ブレンド膜の透過型 電子顕微鏡写真 (TEM) では PMSP 中に楕円状 の PPP が分散している相分離構造が観察され た . 例えば, $10 \mathrm{wt} \% \mathrm{PPP}$ を含有したブレンド 膜中の PPP ドメインは幅 $0.7 \sim 0.9 \mu \mathrm{m}$, 長さ 5 $\mu \mathrm{m}$ の楕円形であった ${ }^{4)}$.

本研究では, PPP の構造に類似した一置換ア セチレン高分子であるポリ (フェニルアセチレン) (PPA, Fig. 1) と PMSP とのブレンド膜の気体 透過特性について検討した。

\section{2. 実験方法}

\section{1 ブレンド膜の調製}

$\mathrm{PMSP}^{5)}$ は，先に合成したサンプルをそのま ま使用した。

PPA は, 常法 ${ }^{6}$ に従い, フェニルプロピン (PA) を, $\mathrm{WCl}_{6}-\mathrm{Ph}_{4} \mathrm{Sn}(1: 1)$ を触媒としてシ クロヘキサン中にて重合させた. 反応は $30^{\circ} \mathrm{C} に$ て 24 時間行った. 収率は, 90〜100\%であった。 生成物は, 赤外吸収スペクトルと核磁気共鳴スペ クトルによる構造解析により PPA である事を同
膜 (MEMBRANE), Vol. 24 No. 3 (1999)

183

定した.

製膜は先に報告した方法 ${ }^{3)}$ と同様にして行っ た. まず, PMSP と PPA のトルエン溶液を調 製し，水平なガラスシャーレ上にキャストした。 10 日前後で溶剤を蒸発させ, その後, 微量の残 存溶剤を取り除くため真空乾燥した. フィルムは ガラスシャーレから剝離後, 経時変化による劣化 を防ぐために，使用直前までメタノール中に浸漬 保存しておいた。

\section{2 キャラクタリゼーション}

PMSP, PPA および PPP の密度は, 各フィ ルムの体積と質量から算出した. そして, これら の密度を用いて, (1)式より自由体積分率 (FFV) を算出した。

$$
F F V=\frac{V-1.3 V_{w}}{V}
$$

ここで, $\mathrm{V}$ はフィルムの密度の逆数から算出した 比体積, $\mathrm{V}_{w}$ は Bondi の原子団寄与法 (group contribution method) により算出されたファン デルワールス体積である ${ }^{7)}$ FFV はゴム状高分 子について用いられる概念であるが，ガラス状高 分子（例えばポリスルホン）においても側鎖や主 鎖の構造を変化させた同系列の高分子の気体透過 係数の变化を相対的に比較する際に利用されてい $3^{8)}$.

高分子の分子間凝集エネルギー密度 (CED) と 溶解度パラメーター (SP) は, Fedors ${ }^{9)}$ の原子 団寄与法を用いて算出した. 原子団寄与法を用い て CED と SP を算出する方法は他にも, Small, Hoy, Van Krevelen 等の方法 ${ }^{10)}$ があるが, PM $\mathrm{SP}$ に含まれる $\mathrm{Si}$ (シロキサン結合でない $\mathrm{Si}$ )に 関する係数がないため Fedors の係数を用いた.

\section{3 気体透過測定}

気体透過測定は, 低真空法気体透過装置を用い,

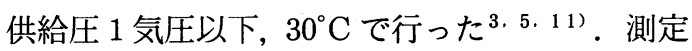
には, 水素, 酸素, 窒素, 二酸化炭素およびメ夕 ンを使用した。

先に述べたが，フィルムは，使用直前までメ夕 
<smiles>CC(C)(C)C1(C)CC1(C)C</smiles>

(a) PMSP<smiles>CC(C)=CC(C)C</smiles>

(b) PPP<smiles>CC=CC(C)C</smiles>

(c) PPA
Fig. 1 Chemical structures of poly(1-trimethylsilyl-1-propyne) [PMSP], poly(1-phenyl-1-propyne) [PPP], and poly (phenylacetylene) [PPA].

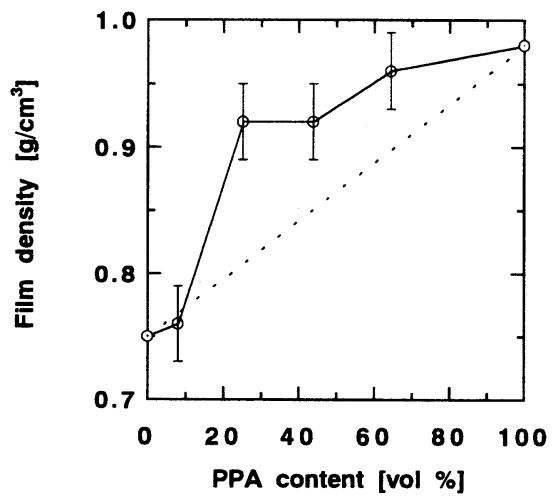

Fig. 2 Effect of PPA concent on film density in PMSP/PPA blends.

ノール中に保存しておいた. この際, フィルムは, メタノールにより少し膨潤している. 測定は, メ タノールから膜を取り出し乾燥させ, フィルムの 収縮がおさまった後に行った. 詳細は, 前報に従っ

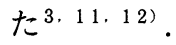

\section{3. 結果と考察}

\section{1 PMSP, PPA および PPP の一般特性}

Table 1 に, PMSP, PPA および PPP のフィ ルム密度, FFV, SP と CED を示す. PMSP と 比較して, PPA とPPP は高い密度, 低い FFV 值, 高い SP 值, そして高い CED 值を有してい る. PPA と PPP との間では, それらの差は小 さいが, PPA はPPP と比較して低い密度, 高 い FFV 值, 高い SP 値, そして高い CED 值を 有している.

$\mathrm{CED}$ の大きな方が高分子鎖のパッキングが密
Table 1 Properties of poly(1-trimethylsilyl-1-propyne) (PMSP), poly(phenylacetylene) (PPA), and poly(1-phenyl-1-propyne) (PPP)

\begin{tabular}{ccccc}
\hline Polymers & $\begin{array}{c}\text { Density } \\
\left(\mathrm{g} / \mathrm{cm}^{3}\right)\end{array}$ & $\begin{array}{c}\text { FFV } \\
(-)\end{array}$ & $\begin{array}{c}\mathrm{SP} \\
{\left[\left(\mathrm{J} / \mathrm{cm}^{3}\right)^{1 / 2}\right]}\end{array}$ & $\begin{array}{c}\mathrm{CED} \\
\left(\mathrm{J} / \mathrm{cm}^{3}\right)\end{array}$ \\
\hline PMSP & 0.75 & $0.29^{13)}$ & $15.8^{11)}$ & 250 \\
PPA & 0.98 & 0.26 & 22.6 & 511 \\
PPP & 1.0 & $0.22^{4)}$ & $21.9^{11)}$ & 480 \\
\hline
\end{tabular}

になり,フィルム密度から算出された FFV は小 さくなるものと推察される. PMSP とフェニル アセチレン重合体 (PPA および PPP) とでは, この関係が成立している，值の差は小さいが, PPA はPPP と比較して高い CED 值を有して いるが FFV は大きな值を示した.

高分子ブレンドにおいて, SP 值の近い高分子 同士のブレンドの方が相溶性に優れる事が推定さ れる ${ }^{9,10)}$. SP 值の比較より, PMSP/PPP の方 が, PMSP/PPA より相溶性に優れる事が推察 された。

また, PMSP, PPA および PPP のガラス転 移温度は $200^{\circ} \mathrm{C}$ 以上であり, $\mathrm{PMSP} / \mathrm{PPA}$ およ び PMSP/PPP ブレンドのガラス転移温度も $200^{\circ} \mathrm{C}$ 以上であった.

\section{2 PPA 含有量の効果}

Fig. 2に, ブレンド膜の密度と PPA 含有量と の関係を示す．ブレンド膜の密度測定は，少なく とも 3 枚のフィルムに対して行った. サンプルの 違いによる誤差は $\pm 0.03 \mathrm{~g} / \mathrm{cm}^{3}$ 以内であった。

PPA の含有量が増加するにつれてフィルムの 密度は増加した. 特に PPA の含有量が 10 から 20 vol\% の間で急激な密度の増加が観察された。 PPA 含有量 8 vol\% と 25 vol\% のブレンド膜の 密度は, 各々 $0.76 \mathrm{~g} / \mathrm{cm}^{3}$ と $0.92 \mathrm{~g} / \mathrm{cm}^{3}$ であり, その密度の差は $0.16 \mathrm{~g} / \mathrm{cm}^{3}$ であった. PPA 含 有量が $20 \mathrm{vol} \%$ 以上においては, ブレンド膜の 密度は $0.9 \mathrm{~g} / \mathrm{cm}^{3}$ 以上であった.

Fig. 3(a)(b)に，(a)ブレンド膜の気体透過係数お よび(b)PMSP とブレンド膜の気体透過係数の比 に及ぼす PPA 含有量の効果を示す. PPA 単独 のフィルムは非常に脆く, 気体透過性の測定は不 

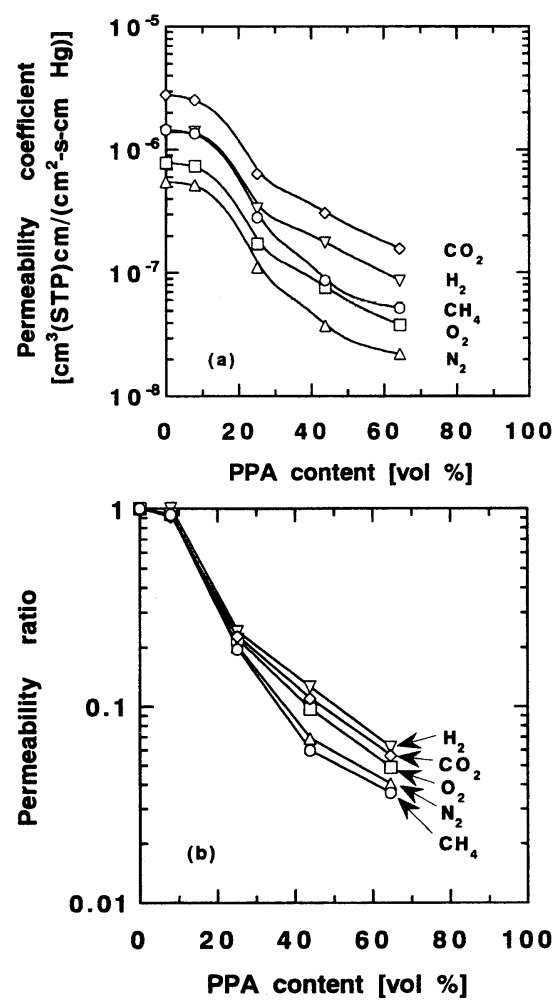

Fig. 3 Effect of PPA content on (a) gas permeability coefficients and (b) gas permeability ratios for various gases in PMSP/PPA blends at $30^{\circ} \mathrm{C}$.

Gas permeability ratio is defined as (permeability of blend)/(permeability of PMSP).

可能であった. 今回用いた PMSP/PPA ブレン ド膜では, $30^{\circ} \mathrm{C}$ で 1 週間の真空保存期間中に気 体透過係数の変化は観察されなかった. 気体透過 係数は，この 1 週間以内の值を用いた. Fig. 3(a) には各々の PPA 含有量において, 少なくとも 3 枚のブレンド膜に対して測定した気体透過係数の 平均値を示した. 気体透過係数のサンプルの違い による誤差は最大でも $\pm 5 \%$ であったが, エラー バーは Fig. 3(a)の○印等の中におさまったため 表示されていない.

Fig. 3(a)において PPA の含有量が増加するに つれてブレンド膜の気体透過係数は減少した. ま た, Fig. 3(b)より PMSP とブレンドとの気体透
過係数の比は, PPA 含有量の増加に伴い分子径 の大きな気体程小さな值を示した。すすなわち透過 係数比の大きさは $\mathrm{H}_{2}>\mathrm{CO}_{2}>\mathrm{O}_{2}>\mathrm{N}_{2}>\mathrm{CH}_{4}$ の順 序であった.

前報5, 11) より PMSP の気体透過係数の大き さは, $\mathrm{CO}_{2}>\mathrm{CH}_{4} \geqq \mathrm{H}_{2}>\mathrm{O}_{2}>\mathrm{N}_{2}$ の順序であった. $\mathrm{PMSP}$ の $\mathrm{CH}_{4}$ と $\mathrm{H}_{2}$ の気体透過係数は同程度の 値であったが, Fig. 3(a)より PPA 含有量の増加 に伴い, $\mathrm{H}_{2}$ より分子径の大きい $\mathrm{CH}_{4}$ の気体透 過係数の減少が大きかったため, 両者の気体透過 係数の差が広がった。 それ故, PPA 含有量が 20 vol\%より高い領域における気体透過係数は, $\mathrm{H}_{2}$ の方が $\mathrm{CH}_{4}$ より高い值を示した（気体透過係数 の大きさ: $\left.\mathrm{CO}_{2}>\mathrm{H}_{2}>\mathrm{CH}_{4}>\mathrm{O}_{2}>\mathrm{N}_{2}\right)$.

高分子ブレンドに対して, それらの気体透過係 数とブレンド組成比との関係が研究されてきてい $3^{14 \sim 17)}$. 均一ブレンドおよびミクロ相分離構 造を有するブレンドの気体透過係数は, 各々(2)式 および(3)式により示される14 17).

$$
\log \mathrm{P}=\phi_{1} \log \mathrm{P}_{1}+\phi_{2} \log \mathrm{P}_{2}
$$

$$
\mathrm{P}=\mathrm{P}_{1} \frac{\mathrm{P}_{2}+2 \mathrm{P}_{1}-2 \Phi_{2}\left(\mathrm{P}_{1}-\mathrm{P}_{2}\right)}{\mathrm{P}_{2}+2 \mathrm{P}_{1}+\Phi_{2}\left(\mathrm{P}_{1}-\mathrm{P}_{2}\right)}
$$

ここで, $\mathrm{P}_{1}$ と $\mathrm{P}_{2}$ は, 成分 1 と 2 の気体透過係 数, $\phi_{1}$ と $\phi_{2}$ は, 成分 1 と 2 の体積分率である. (3)式中において, 成分 1 と 2 は各々, 連続相, 不 連続相である.

PMSP/PPA ブレンドにおいて, PPA フィル ムの気体透過係数が測定できないため, 上式に対 応する理論曲線が計算できない，報告されている 種々の高分子ブレンドの気体透過係数とブレンド 組成比との関係によると，(2)式に従う均一ブレン ドの場合, 気体透過係数の対数と組成比との関係 が直線となる. しかしながら, Fig. 3(a)に示した $\mathrm{PMSP} / \mathrm{PPA}$ ブレンド膜の実験結果は, 先に述 べた測定誤差を考慮しても完全な直線関係ではな く, 均一ブレンドを表す(2)式に相当していなかっ た. PPA 含有量が増加するにつれてブレンド膜 の密度が高くなり気体透過係数は低い值を示し た.この事より Fig. 3(a)の気体透過係数と PPA 


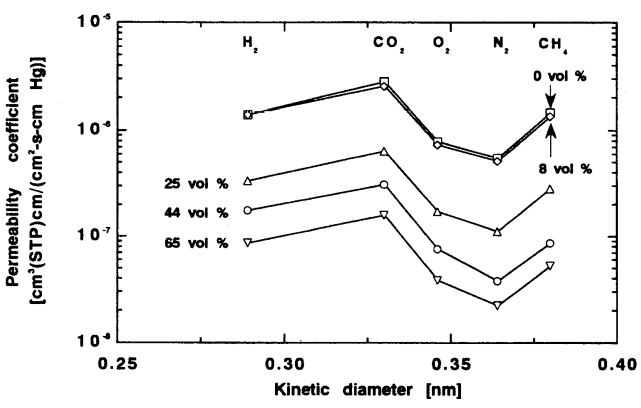

Fig. 4 Gas permeability coefficients for various gases in PMSP/PPA blends as a function of penetrant kinetic diameter at $30^{\circ} \mathrm{C}$.

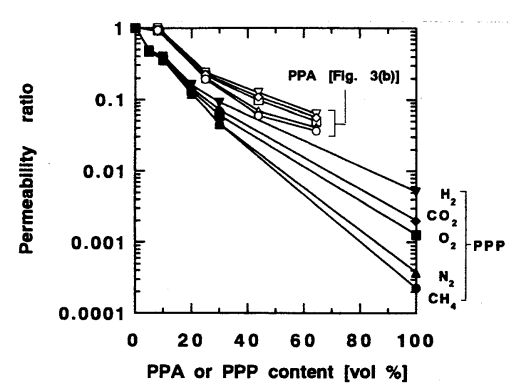

Fig. 6 Effect of PPA or PPP content on gas permeability ratios for various gases in PMSP/PPA and PMSP/PPP blends at $30^{\circ} \mathrm{C}$.

Gas permeability ratio is defined as (permeability of blend)/(permeability of PMSP). PMSP/PPP blends : deta from ref. 3.

含有量との関係と Fig. 2 のフィルム密度と PPA 含有量との関係の間に相関が得られた。

Fig. 4 にブレンド膜の気体透過係数と気体の 分子径との関係を示す.先に述べたように, PPA 含有量が増加するにつれてブレンド膜の気体透過 係数は減少したが，ブレンド膜の気体透過係数と 気体の分子径との関係は，PMSP と同様の傾向 を示した。

ポリスルホンのような一般的なガラス状高分子 の場合，その気体透過性は気体の分子径が大きく なるにつれて減少していく18)。しかし, PMSP は二酸化炭素や炭化水素の非常に高い溶解性の効

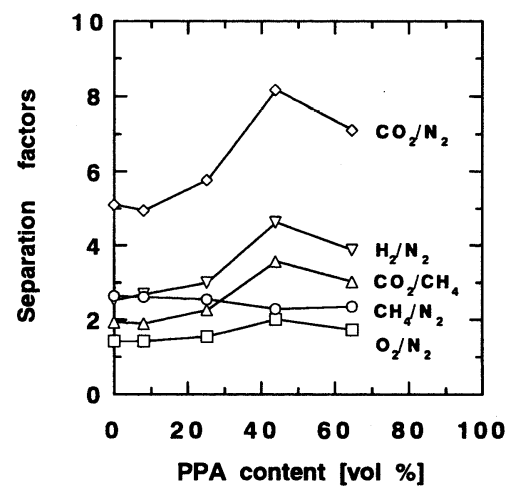

Fig. 5 Effect of PPA content on gas separation factors of PMSP/PPA blends at $30^{\circ} \mathrm{C}$.

果により，例えば炭化水素においては分子径の増 加につれて気体透過係数は増加するという特殊な 現象を示す ${ }^{18)}$ 。

Fig. 4 より, PMSP と相互作用の小さい $\mathrm{H}_{2}$, $\mathrm{O}_{2}, \mathrm{~N}_{2}$ においては, 分子径が大きくなるにつれ て気体透過係数は, 減少していった。一方, PM$\mathrm{SP}$ に対して高い溶解性を示す $\mathrm{CO}_{2}$ と $\mathrm{CH}_{4}$ は単 純に分子径の大きさに依存せず, $\mathrm{H}_{2}, \mathrm{O}_{2}, \mathrm{~N}_{2}$ か ら予想される気体透過係数よりも高い值を示した. ブレンド膜においても同様の傾向が観察された.

Fig. 5 に PPA 含有量と種々の気体分離係数 との関係を示す. PMSP と比べて, PPA の添加 により $\mathrm{CH}_{4} / \mathrm{N}_{2}$ 以外の気体の分離係数は増加し た.これは，Fig. 3(b)の結果より PPA の添加に より PMSP とブレンドの気体透過係数の比が気 体の分子径が大きくなるにつれて小さくなった事 に起因する.この $\mathrm{CH}_{4} / \mathrm{N}_{2}$ の減少は, $\mathrm{CH}_{4}$ の PMSP に対する透過係数比の減少が $\mathrm{N}_{2}$ の透過 係数比の減少より大きかったためである．その他 の分子径の小さい気体と大きい気体の組み合わせ では, PPA 含有量の増加に伴い気体分離係数は 一旦増加したが, PPA 含有量が 50 vol\%付近か ら減少していった。

\section{$3.3 \mathrm{PMSP} / \mathrm{PPA}$ と PMSP/PPP ブレンド との比較}

Fig. 6 に PMSP/PPA ブレンド膜の気体透過 
係数比と, 前報 [3] にで報告した PMSP/ PPA ブレンドとの比較の図を示す. PMSP/ PPAブ レンドと比較して, PMSP/PPP のブレンドの方 が, 同程度の PPA と PPP 含有量において, 低 い気体透過係数を示した. また, PMSP/PPAブ レンド膜と同様に, $\mathrm{PMSP} / \mathrm{PPP}$ ブレンド膜にお いても, PPP 含有量の増加に伴う気体透過係数 の減少は, 分子径の大きな気体程大きな度合を示 した。

Fig. 6 で PMSP/PPA ブレンドの方が PM$\mathrm{SP} / \mathrm{PPP}$ ブレンドより高い気体透過係数を示し た事と Table 1 において PPA の FFV が PPP より大きい事より, PPA フィルムの気体透過係 数が測定できた場合, PPP より高い気体透過係 数を示すことが推察される.

\section{4. 結 論}

本研究では PMSP/PPA ブレンド膜の気体透 過特性を検討し, 以下の結論を得た.

1 : ブレンド中の PPA 含有量が増加するにつ れて, フィルム密度は増加して気体透過係数は減 少したが, 気体の分離係数は増加した。この際の 気体透過係数とPPA 含有量との関係は, 均一ブ レンドを表す関係式に完全には相当していなかっ た.

$2:$ ブレンド膜の気体透過係数と気体の分子径 との関係は PMSP と同様な傾向を示した. すな わち PMSP と相互作用の小さい $\mathrm{H}_{2}, \mathrm{O}_{2}, \mathrm{~N}_{2}$ に おいては分子径が大きくなるにつれて気体透過係 数は減少したが, PMSP に対して高い溶解性を 示す $\mathrm{CO}_{2}$ と $\mathrm{CH}_{4}$ は単純に分子径の大きさに依存 せず, $\mathrm{H}_{2}, \mathrm{O}_{2}, \mathrm{~N}_{2}$ から予想される気体透過係数 より高い值を示した.

$3:$ すでに報告している PMSP/PPP ブレンド と比較して, 同じ PPA または PPP 含有量にお いて PMSP/PPA ブレンド膜の方が PMSP/ PPP ブレンド膜より気体透過係数は大きかった. またPPA フィルムの気体透過係数が測定できた 場合, PPP より高い気体透過係数を示すことが 推察された.

\section{文 献}

1）増田俊夫：高分子, 47 336-337 (1998).

2) 永井一清: 膜, 22 206-210 (1997).

3) Nagai $K$, Mori M, Watanabe $T$, Nakagawa $T$ : J. Polym. Sci. : Part B : Polym. Phys., 35 119-131 (1997).

4) (a) Morisato A, Shen H C, Sankar S S, Freeman B D, Pinnau I, Casillas C G : J. Polym. Sci. : Part B : Polym. Phys., 34 2209-2222 (1996). (b) Toy L G, Freeman B D, Spontak R J, Morisato A, Pinnau I : Macromolecules, 30 4766-4769 (1997).

5) Nagai K, Higuchi A, Nakagawa T : J. Appl. Polym. Sci., 54 1207-1217 (1994).

6) Masuda T, Higashimura T : Adv. Polym. Sci, 81 121-165 (1987).

7) Bondi A : J. Phys. Chem., 68 441-451 (1964).

8) Pixton M R, Paul D R : Chapter 3 in Polymeric Gas Separation Membranes, Paul D R, Yampol'skii Yu P eds. CRC Press, Boca Raton, p. 83, 1994.

9) Fedors R F : Polym. Eng. Sci., 14 147-154 (1974).

10) Van Krevelen D W, Properties of Polymers, 3rd ed., Elsevier, Amsterdam, The Netherlands, p. 189, 1990.

11) Nagai K, Higuchi A, Nakagawa $T:$ J. Polym. Sci. : Part B :Polym. Phys., 33 289-298 (1995).

12) Nagai $K$, Nakagawa $T: J$. Membrane Sci., 105 261-272 (1995).

13) Freeman B D, Hill A J, Chapter 21 in Structure and Properties of Glassy Polymers, Tant M R, Hill A J Eds., ACS Symposium Series 710, American Chemical Society, 306-325 (1998).

14) Barnabeo A E, Creasy W S, Robeson L M : J. Polym. Sci., Polym. Chem. Ed., 13 19791986 (1975).

15) Barrie J A, Ismail J B : J. Membrane Sci., 13 197-204 (1983).

16) Paul D R: J. Membrane Sci., 18 75-86 (1984).

17) Kim C K, Aguilar-Vega M, Paul D R : J. Polym. Sci. : Part B : Polym. Phys., 30 11311142 (1992).

18) Freeman B, Pinnau I : Trends Polym. Sci., 5 167-173 (1997).

（受付 1998 年 11 月 11 日 修正校受付 1999 年 3 月 12 日 掲載決定 3 月 24 日） 